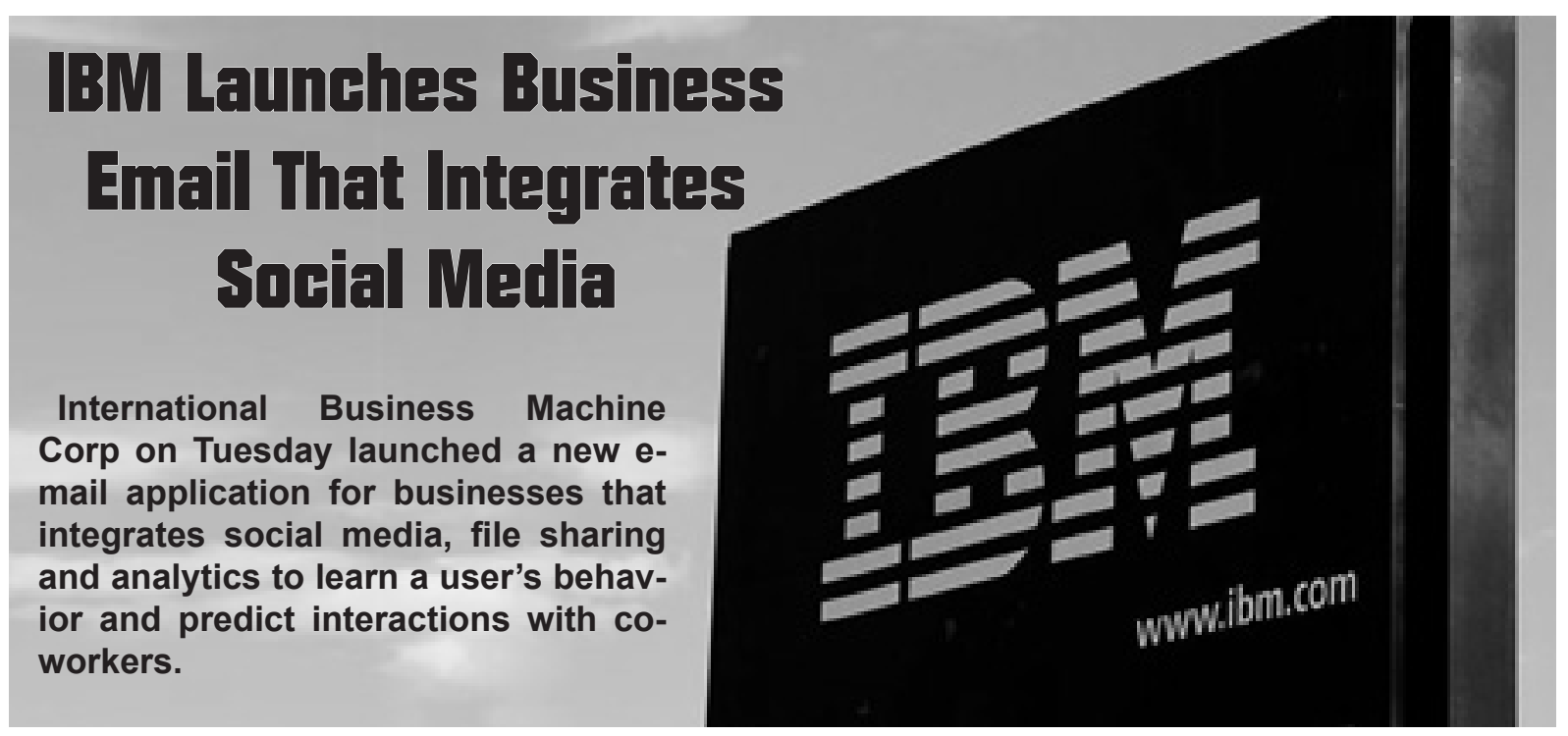

The application is part of IBM's attempt to shift its focus to cloud computing and data analytics from the hardware services that had long been the company's bread and butter.

The new e-mail service, known as IBM Verse, includes a built-in personal assistant that can learn from a user's behavior and draft responses to e-mails based on similar previous interactions.

It also allows users to transform e-mail content into threads for blogs and social media, view the relationships between different employees in an e-mail, mute a chain and search through attachments.

The e-mail' $s$ interface pins a user's most frequent contacts, schedule and lists of assignments to a dashboard for easy access.

"We came at this from the perspective that this is about changing the game, not just incremental improvements in e-mail," Jeff Schick, IBM's general manager of social solutions, told Reuters.

IBM's enterprise mail service, known as Notes, is used by 25,000 companies worldwide and more than 50,000 use IBM's social platform for businesses, IBM Connections. The company hopes IBM Verse will eventually replace Window's popular Outlook.

The free initial model will include limited mailbox sizes and file sharing. A paid version with additional features and data allowance will be available in January 2015.

IBM is not the only company trying to give e-mail a makeover. In October, Google Inc launched an e-mail service called "Inbox" that will better organize e-mails and display information such as appointments, flight bookings and package deliveries in a more user-friendly way.
But unlike Google, IBM Verse will not sell the data it gathers about users to advertisers, a selling point critical for businesses concerned about privacy and security. The service is delivered through cloud computing and will be available in IBM's Cloud Marketplace.

(Reporting by Marina Lopes; Editing by Dan Grebler)

\section{The Importance of Produrtivity}

One company that seems to have found a bit of success with its social network is ATB Financial, which claims it has increased productivity by 30 percent using a tool called AtTask. It's also apparently been able to track five times more information with the tool, a number it came up with after watching how its marketing department used it over the course of a year.

AtTask, as the name implies, is focused on task management, but it includes tools for things like document management, workflows, approvals, reports and dashboards. It is not quite as slick in that looks-like-an-iPad-app kind of way, but it certainly has a slew of features. Additionally, it starts at $\$ 30$ per month per user, a truly enterprise level pricing structure.

As to how it compares to the dozens of similar tools out there, one top notch place to start is the recent Gartner MQ for Workplace Social Software. It features the usual leaders, challengers, visionaries and niche categories of industry heavyweights, but also a long list of other tools that aren't included in the report.

AtTask is not in this MQ or on the excluded list, but Microsoft, IBM, Jive, Salesforce, NewsGator, Atlassian, Tibco and VMWare are. Instead, Gartner includes AtTask in the Cloud based IT Project and Portfolio Management category, an IT driven category where it competes with tools like OracleInstantis, EPM Live and Clarizen, for example. 